\title{
Should developmental prosopagnosia, developmental body agnosia, and developmental object agnosia be considered independent neurodevelopmental conditions?
}

Article

Accepted Version

Gray, K. L. H. and Cook, R. (2018) Should developmental prosopagnosia, developmental body agnosia, and developmental object agnosia be considered independent neurodevelopmental conditions? Cognitive Neuropsychology, 35 (1-2). pp. 59-62. ISSN 1464-0627 doi:

https://doi.org/10.1080/02643294.2018.1433153 Available at https://centaur.reading.ac.uk/75098/

It is advisable to refer to the publisher's version if you intend to cite from the work. See Guidance on citing.

To link to this article DOI: http://dx.doi.org/10.1080/02643294.2018.1433153

Publisher: Taylor \& Francis

All outputs in CentAUR are protected by Intellectual Property Rights law, including copyright law. Copyright and IPR is retained by the creators or other copyright holders. Terms and conditions for use of this material are defined in the End User Agreement. 


\section{www.reading.ac.uk/centaur}

\section{CentAUR}

Central Archive at the University of Reading

Reading's research outputs online 
In press at Cognitive Neuropsychology

Should developmental prosopagnosia, developmental body agnosia, and developmental object agnosia be considered independent neurodevelopmental conditions?

\author{
Katie L. H. Gray ${ }^{1} \&$ Richard Cook $^{2 *}$ \\ ${ }^{1}$ School of Psychology and Clinical Language Sciences, \\ University of Reading, Reading, U.K. \\ ${ }^{2}$ Department of Psychological Sciences, \\ Birkbeck, University of London, London, U.K. \\ ${ }^{*}$ Corresponding author: \\ richard.cook@bbk.ac.uk \\ Department of Psychological Sciences, \\ Birkbeck, University of London, \\ London, U.K.
}




\section{Introduction}

Having reviewed 238 cases of developmental prosopagnosia (DP) that met their criteria, Geskin and Behrmann (2017) found that only $\sim 20 \%$ exhibit normal object recognition. This figure likely underestimates the proportion of individuals with a selective face perception deficit ('pure cases') as many DPs exhibiting accurate object recognition were excluded from the authors' primary analysis because response time data were unavailable. Nevertheless, it is clear that object recognition problems frequently co-occur with DP. What does this mean? Geskin and Behrmann argue that this indicates that DP is caused by a domain-general cognitive-perceptual deficit. We suggest an alternative interpretation. According to the independent disorders hypothesis, forms of developmental agnosia affecting faces (DP), objects (developmental object agnosia; DOA), and bodies (developmental body agnosia; DBA) are best characterised as independent neurodevelopmental conditions that co-occur; that is to say, the incidence of DOA and DBA is higher in DP than in the wider population. We argue that this co-occurrence reflects common genetic or environmental risk factors.

\section{The independent disorders hypothesis}

Co-occurrence is a common feature of many neurodevelopmental conditions. For example, numerous conditions co-occur with autism spectrum disorder (ASD) including attention deficit and hyperactivity disorder (Leitner, 2014), developmental coordination disorder (Dziuk et al., 2007), developmental alexithymia (Bird \& Cook, 2013), specific language impairment (Conti-Ramsden, Simkin, \& Botting, 2006), dyslexia (Jones et al., 2009) and synesthesia (Baron-Cohen et al., 2013). While each of these conditions is an independent construct - each can occur in the absence of other disorders - they occur with a greater incidence in ASD than in the wider population. While co-occurrence is regarded as the "norm 
rather than the exception' in psychiatry, this feature of neurodevelopmental conditions is often overlooked by vision researchers.

Some co-occurrence likely reflects the fact that development is an inherently recursive process; atypicality in one area may have knock-on developmental consequences in other areas. However, genetic or environmental factors that predispose an individual to one condition, also appear to increase their risk of developing others (Bishop \& Rutter, 2008; Gilger \& Kaplan, 2001; Kaplan, Dewey, Crawford, \& Wilson, 2001). One possibility is that a predisposition to atypical neural development - including reduced white matter integrity (Fields, 2008) and aberrant neuronal migration (Ramus, 2004) - leaves individuals vulnerable to multiple neurodevelopmental conditions. In line with this possibility, we speculate that i) individuals do not inherit DP per se, but rather a susceptibility to aberrant structural development of occipito-temporal cortex (also see Susilo \& Duchaine, 2013); and ii) this predisposition represents a common risk factor for DP, DBA, and DOA.

Many DPs, for example, exhibit reduced integrity of the inferior longitudinal fasciculus; a white matter tract connecting occipital and temporal cortices. Sometimes, these structural differences are highly localised (Song et al., 2015). In other cases, widespread structural differences are seen throughout occipito-temporal cortex (Thomas et al., 2009). A DP's white matter profile may not only determine the type of face perception deficits they exhibit, but also whether or not they experience perceptual deficits for non-face stimuli (e.g., Gomez et al., 2015). Where poor tract integrity impairs information exchange within body and object processing networks, individuals may experience deficits of body and object perception, respectively. Consistent with previous demonstrations of functional dissociation (Moscovitch, Winocur, \& Behrmann, 1997; Pitcher, Charles, Devlin, Walsh, \& Duchaine, 2009), the 
independent disorders hypothesis supposes that aberrant structural development can, in principle, selectively impair the perception of faces, bodies, or objects. Under this view, forms of developmental agnosia affecting faces, bodies, and objects are therefore characterized as independent conditions.

\section{The evidence}

Pure cases. If face and object recognition deficits co-occur because a common domaingeneral process (e.g., configural processing) is impaired, pure cases of DP, DBA, or DOA should not exist. In contrast, the independent disorders hypothesis explicitly predicts pure cases of DP, DBA, and DOA. Consistent with the latter, the analysis of Geskin and Behrmann confirms the existence of pure cases of DP. Similarly, case studies have described individuals with DOA in the absence of co-occurring face recognition difficulties (Germine, Cashdollar, Düzel, \& Duchaine, 2011). Relative to DP, we acknowledge that fewer cases of pure DOA and DBA have been described. It is possible that the organisation of occipitotemporal cortex makes cases of pure DOA and DBA less likely. Alternatively, individuals with pure forms of DOA and/or DBA may be less likely to approach researchers given that body and object recognition difficulties are likely to be less socially debilitating than face recognition deficits. Crucially, however, the relative infrequency of pure cases (of DP, DOA or DBA) compared to instances of co-occurrence in no way undermines the independent disorders hypothesis; one only requires a handful of individuals, tested thoroughly, to demonstrate the dissociability of these conditions.

Covariation of deficits. The domain-general account offered by Geskin and Behrmann predicts that the extent of an observer's deficit in one category ought to relate closely to their relative performance in other categories. However, existing results argue against this view. For example, Zhao and colleagues (2016) found a non-significant correlation between face 
and object (flowers, birds, and cars) discrimination accuracy in a sample of 64 DPs (see also Biotti \& Cook, 2016). Similarly, we recently observed little or no correlation between ability to discriminate cars and bodies, assessed using closely matched tasks, in a sample of 20 DPs (Biotti, Gray, \& Cook, 2017). Results such as these argue against the view that face and nonface deficits arise from a single domain-general impairment. Instead, idiosyncratic patterns of face, body, and object recognition ability support the independent disorders hypothesis. These findings further highlight the value of testing DPs on a wide range of object recognition tasks. The domain-general hypothesis predicts that observers with DP should have difficulties recognising a wide range of non-face objects (e.g., impaired configural processing should lead to poor perception of any object class that requires configural processing). Selective impairment in one or two object categories is therefore weak evidence for a domain-general perceptual deficit.

Familial heterogeneity. Where individuals inherit susceptibility to aberrant structural development, this predisposition may manifest idiosyncratically. The independent disorders hypothesis therefore allows that familial cases of DP may present with very different cognitive-perceptual profiles. For example, shared susceptibility might leave one family member with a highly selective case of apperceptive prosopagnosia, and another with an associative prosopagnosia with co-occurring DOA and DBA. Early results provide some support for this possibility. For example, having tested seven members of a single family who all reported lifelong face recognition difficulties, Schmalzl and colleagues (2008) found that the cases differed widely in terms of their face processing difficulties and the specificity of their deficits. With this finding in mind, we speculate that family members of DPs may sometimes show signs of DOA and/or DBA, even where they exhibit typical face recognition. 
Co-occurrence with autism. The independent disorders hypothesis predicts that individuals predisposed to DP should be more likely to develop other neurodevelopmental conditions, such as ASD, and vice versa. It is beyond doubt that DP and ASD are independent conditions; for example, it is known that DP can occur in the absence of wider sociocognitive difficulties (Duchaine, Murray, Turner, White, \& Garrido, 2009). Nevertheless, face recognition difficulties are more common in ASD than in the general population (e.g., Hedley, Brewer, \& Young, 2011). Where observed, it may be fruitful to view these face recognition deficits as co-occurring DP. Of particular interest, there appears to be a huge range of face recognition abilities in the ASD population; whereas some individuals experience severe lifelong face recognition problems that closely resemble DP (Kracke, 1995), many others exhibit entirely typical face perception (Hedley et al., 2011). While this pattern challenges the view that deficits in this domain are a core feature of ASD per se, it is precisely what one might expect if a subset of the ASD population experience co-occurring DP. 


\section{References}

Baron-Cohen, S., Johnson, D., Asher, J., Wheelwright, S., Fisher, S. E., Gregersen, P. K., \& Allison, C. (2013). Is synaesthesia more common in autism? Molecular Autism, 4, 16.

Biotti, F., \& Cook, R. (2016). Impaired perception of facial emotion in developmental prosopagnosia. Cortex, 81, 126-136.

Biotti, F., Gray, K. L. H., \& Cook, R. (2017). Impaired body perception in developmental prosopagnosia. Cortex, 93, 41-49.

Bird, G., \& Cook, R. (2013). Mixed emotions: the contribution of alexithymia to the emotional symptoms of autism. Translational Psychiatry, 3, e285.

Bishop, D. V. M., \& Rutter, M. (2008). Neurodevelopmental disorders: conceptual issues. In M. Rutter, D. V. M. Bishop, D. Pine, S. Scott, J. Stevenson, E. A. Taylor \& A. Thapar (Eds.), Rutter's Child and Adolescent Psychiatry (pp. 32-41). Oxford, UK: Blackwell.

Conti-Ramsden, G., Simkin, Z., \& Botting, N. (2006). The prevalence of autistic spectrum disorders in adolescents with a history of specific language impairment (SLI). Journal of Child Psychology and Psychiatry, 47, 621-628.

Duchaine, B., Murray, H., Turner, M., White, S., \& Garrido, L. (2009). Normal social cognition in developmental prosopagnosia. Cognitive Neuropsychology, 26, 620-634. 
Dziuk, M. A., Larson, J. C., Apostu, A., Mahone, E. M., Denckla, M. B., \& Mostofsky, S. H. (2007). Dyspraxia in autism: association with motor, social, and communicative deficits. Developmental Medicine and Child Neurology, 49, 734-739.

Fields, R. D. (2008). White matter in learning, cognition and psychiatric disorders. Trends in Neurosciences, 31, 361-370.

Germine, L., Cashdollar, N., Düzel, E., \& Duchaine, B. (2011). A new selective developmental deficit: Impaired object recognition with normal face recognition. Cortex, 47, 598-607.

Geskin, J., \& Behrmann, M. (2017). Congenital prosopagnosia without object agnosia? A literature review. Cognitive Neuropsychology, 22, 1-51.

Gilger, J. W., \& Kaplan, B. J. (2001). Atypical brain development: a conceptual framework for understanding developmental learning disabilities. Developmental Neuropsychology, 20, 465-481.

Gomez, J., Pestilli, F., Witthoft, N., Golarai, G., Liberman, A., Poltoratski, S., Yoon, J., \& Grill-Spector, K. (2015). Functionally defined white matter reveals segregated pathways in human ventral temporal cortex associated with category-specific processing. Neuron, 85, 216-227.

Hedley, D., Brewer, N., \& Young, R. (2011). Face recognition performance of individuals with Asperger syndrome on the Cambridge Face Memory Test. Autism Research, 4, 449-455. 
Jones, C. R., Happe, F., Golden, H., Marsden, A. J., Tregay, J., Simonoff, E., Pickles, A., Baird, G., \& Charman, T. (2009). Reading and arithmetic in adolescents with autism spectrum disorders: peaks and dips in attainment. Neuropsychology, 23, 718-728.

Kaplan, B. J., Dewey, D. M., Crawford, S. G., \& Wilson, B. N. (2001). The term comorbidity is of questionable value in reference to developmental disorders: data and theory. Journal of Learning Disabilities, 34, 555-565.

Kracke, I. (1995). Relation between asperger syndrome and prosopagnosia Developmental Medicine and Child Neurology, 37, 563-564.

Leitner, Y. (2014). The co-occurrence of autism and attention deficit hyperactivity disorder in children - what do we know? Frontiers in Human Neuroscience, 8, 268.

Moscovitch, M., Winocur, G., \& Behrmann, M. (1997). What is special about face recognition? Nineteen experiments on a person with visual object agnosia and dyslexia but normal face recognition. Journal of Cognitive Neuroscience, 9, 555-604.

Pitcher, D., Charles, L., Devlin, J. T., Walsh, V., \& Duchaine, B. (2009). Triple dissociation of faces, bodies, and objects in extrastriate cortex. Current Biology, 19, 319-324.

Ramus, F. (2004). Neurobiology of dyslexia: a reinterpretation of the data. Trends in Neurosciences, 27, 720-726.

Schmalzl, L., Palermo, R., \& Coltheart, M. (2008). Cognitive heterogeneity in genetically based prosopagnosia: A family study. Journal of Neuropsychology, 2, 99-117. 
Song, S., Garrido, L., Nagy, Z., Mohammadi, S., Steel, A., Driver, J., Dolan, R. J., Duchaine, B., \& Furl, N. (2015). Local but not long-range microstructural differences of the ventral temporal cortex in developmental prosopagnosia. Neuropsychologia, 78, 195206.

Susilo, T., \& Duchaine, B. (2013). Advances in developmental prosopagnosia research. Current Opinion in Neurobiology, 23, 423-429.

Thomas, C., Avidan, G., Humphreys, K., Jung, K. J., Gao, F., \& Behrmann, M. (2009). Reduced structural connectivity in ventral visual cortex in congential prosopagnosia. Nature Neuroscience, 12, 29-31.

Zhao, Y., Li, J., Liu, X., Song, Y., Wang, R., Yang, Z., \& Liu, J. (2016). Altered spontaneous neural activity in the occipital face area reflects behavioral deficits in developmental prosopagnosia. Neuropsychologia, 89, 344-355. 